\title{
O Processo de Leitura Realizado pela Fórmula "Estudo do Texto" no Livro Didático de Língua Portuguesa
}

The Process of Reading Carried for the Formula “The Study Text” in the Didactic Book of Portuguese Language

Marilúcia dos Santos Domingos STRIQUER *

Resumo: Este artigo apresenta reflexões sobre o trabalho com a compreensão de leitura apresentado pelos livros didáticos de Língua Portuguesa. Partindo de um estudo anterior, realizado por Marcuschi (2001), em que uma taxionomia das perguntas que mais apareceram no Estudo do Texto dos livros didáticos foi elaborada, investigamos, ancorados ao arcabouço teórico da Linguística Aplicada, o Estudo do Texto da obra Linguagem Nova - 50 série (FARACO; MOURA, 2004), sendo esse um dos livros mais adotados nas escolas da rede pública de ensino no Norte do Paraná. Este artigo, portanto, tem o objetivo de apresentar a expansão das tipologias demarcadas por Marcuschi (2001). O resultado demonstra que a expansão ocorreu, principalmente, sobre as questões enquadradas na perspectiva interacionista de leitura (KATO, 1990; SILVA, 1990; SOLÉ, 1998; LEFFA, 1999).

Palavras-chave: Leitura; Estudo do texto; Livro didático.

Abstract: This article presents reflections about the work with reading comprehension presented by didactical books of Portuguese Language. Based on a previous study, made by Marcuschi (2001), in which a Taxonomy of questions which appear more frequently in the Text

* Doutoranda do Programa de Estudos da Linguagem da Universidade Estadual de Londrina. É professora da Universidade Estadual do Norte do Paraná (UENP), campus de Jacarezinho. Contato: marilucia.ss@uol.com.br. 
Study of the didactical books was developed, we investigate, based on the theoretical frame of Applied Linguistics, the Text Study contained in Linguagem Nova $-5^{\text {th }}$ grade (FARACO; MOURA, 2004), considering that this is one of the most adopted books at public schools in North of Parana state. Therefore, this article aims to present the typology expansion marked out by Marcuschi (2001). The result shows the expansion has mainly occurred on the questions framed in interacionist perspective of reading (KATO, 1990; SILVA, 1990; SOLÉ, 1998; LEFFA, 1999).

Key-words: Reading; Text study; Didactical book.

\section{Introdução}

O livro didático (LD) é um material que gera vasto campo de estudos, discussões e críticas, as quais, por vezes, se dividem radicalmente entre o paradoxo "o bem e o mal" ou, por vezes, compreende-se que é um "mal necessário" (SILVA, 1998, p. 43). Baseados em nossa própria experiência em sala de aula, não vemos como o sistema de ensino, hoje, poderia funcionar sem a adoção do livro didático, considerando, entre muitos outros fatores, o contexto social, econômico e cultural brasileiro, pois é na escola que grande parte das crianças tem a oportunidade de estar em contato com textos e livros para suas leituras. Contudo,

[...] o livro didático é (ou deveria ser) apenas um instrumento de apoio à prática pedagógica. Sua utilização só produz bons resultados quando sujeito ao comando do professor, secundada pela criatividade daquele a quem cabe manobrar competentemente esse recurso em sintonia com tantos outros. (SILVA, 1998, p. 119)

No entanto, ao tratarmos sobre a apresentação específica do processo de leitura no livro didático, vale destacarmos estudos como o de Coracini (1999, p.24) que chega a apontar que "a maior parte das aulas de língua materna começam com a frase "Abram o livro à página...., leiam o texto e depois passaremos às perguntas de compreensão ou aos exercícios". Essa atitude, ainda presente em sala de aula nos dias de hoje, acaba por 
estabelecer, para os alunos, um objetivo único de leitura, o de ler para responder exercícios. Fato ainda mais acentuado pela padronização dessa fórmula pelos livros didáticos, a qual, geralmente, é intitulada de "Estudo do texto".

Entre diversas pesquisas realizadas sobre o Estudo do texto dos materiais didáticos, destacamos o de Marcuschi (2001), que constatou que o Estudo do Texto dos livros didáticos de Língua Portuguesa da década de 90, século XX, configurava-se pelo predomínio de questões fundadas exclusivamente no texto, embora diferentes concepções de leitura coexistam na formatação desse tipo de processo; e ainda, elaborou uma taxionomia das perguntas mais presentes, denominada, pelo autor, de "Tipologia das Perguntas de Compreensão em LDP”. O destaque para esse estudo também se justifica pelo fato de essa taxionomia ter sido base de análise de uma pesquisa maior, por nós realizada, intitulada "Objetivos de leitura no livro didático" (STRIQUER, 2007).

$\mathrm{Na}$ referida pesquisa, ao analisarmos, entre outros pontos, especificamente o Estudo do texto do livro didático: Linguagem Nova (FARACO; MOURA, 2004) - $5^{\text {a }}$ série, um dos livros mais utilizados pelas escolas da rede pública de ensino da região norte do Paraná, Núcleo Regional de Ensino Jacarezinho/Pr, nos triênios de 2005-2007 e 2008-2010, fez-se necessário uma ampliação dos tipos demarcados por Marcuschi (2001), uma vez que as questões apresentadas na obra analisada expandiram a taxionomia existente. Portanto, o objetivo deste artigo é apresentar a expansão das tipologias de Marcuschi (2001) que ocorreram na obra Linguagem Nova (FARACO; MOURA, 2004) - $5^{\text {a }}$ série, principalmente no que se refere às questões enquadradas na perspectiva interacionista de leitura.

\section{A leitura no livro didático}

Ao tratarmos do processo de leitura no livro didático, cabe destacar que todo LD no Brasil, a partir de 1997, é submetido a análises e avaliações realizadas por um programa governamental denominado Programa Nacional do Livro Didático (PNLD), a fim de assegurar a qualidade dos livros distribuídos, principalmente, no que se refere às orientações regulamentadas pelos Parâmetros Curriculares Nacionais (PCNs). 
Especificamente, sobre o trabalho com a leitura, definem os PCNs de Língua Portuguesa (BRASIL, 1997, p. 41) que,

A leitura é um processo no qual o leitor realiza um trabalho ativo de construção do significado do texto, a partir dos seus objetivos, do seu conhecimento sobre o assunto, sobre o autor, de tudo o que sabe sobre a língua: características do gênero, do portador, do sistema de escrita, etc. Não se trata simplesmente de extrair informação da escrita, decodificando-a letra por letra, palavra por palavra. Trata-se de uma atividade que implica, necessariamente, compreensão na qual os sentidos começam a ser constituídos antes da leitura propriamente dita.

Dessa forma, os PCNs concebem a leitura em uma perspectiva interacionista, baseada em preceitos teóricos bakhtinianos. Para Bakhtin (2003), o leitor, assim como o autor são partes constitutivas da comunicação verbal, uma vez que são eles os construtores do sentido do texto, de forma que, o autor, ao esperar ser sempre compreendido pelo leitor, elabora seu texto, utilizando-se de recursos expressivos que possam permitir um diálogo entre eles. No entanto, como expõe Bakhtin (2003, p. 272), "toda compreensão plena real e ativamente responsiva não é senão uma fase inicial preparatória da resposta”, assim, o autor não espera apenas a compreensão, pois esta é apenas a primeira etapa do processo na realidade da comunicação. O que se espera do leitor não é uma reprodução dos pensamentos e ideias do autor, mas uma resposta, "uma concordância, uma participação, uma objeção, uma execução, etc.” (BAKHTIN, 2003, p. 272).

É devido a essa resposta que o leitor pode ser visto como sujeito ativo, pois segundo Bakhtin (2003, p. 271), "o ouvinte, ao perceber e compreender o significado (linguístico) do discurso, ocupa simultaneamente em relação a ele uma ativa posição responsiva: concorda ou discorda dele (total ou parcialmente), completa-o, aplicao, prepara-se para usá-lo, etc.”.

Assim, a leitura é vista como um diálogo entre autor e leitor que se realiza através do texto (LEFFA, 1999). Nesse diálogo, o leitor, sujeito ativo, interage com o texto, busca nele as "pistas" construídas pelo autor, chega à compreensão. Em seguida, analisa, reflete, e emite 
um juízo de valor, chega à interpretação. Então concorda ou discorda, completa, aplica, usa as ideias do autor, ou seja, tem uma atitude responsiva ativa.

No entanto, com base nos estudos já realizados sobre o processo de leitura apresentado pelo LD, é possível constatar a presença da mecanicidade da leitura, que ocorre pelo ato constante de ler e preencher exercícios sobre a compreensão leitora (KLEIMAN, 1993, 2000), promovendo a passividade do leitor.

Por exemplo, Magnani (1989) chega a afirmar que a uniformidade de questionamentos da compreensão leitora é o que estabelece ao aluno uma "atitude meramente passiva e reprodutora frente a um texto dado como 'exemplar”' (p. 33), pois não é o aluno que formula suas perguntas em busca de compreender o texto, em busca do que é necessário saber, é o autor do LD que as elabora. Assim, o importante e o necessário ficam determinados pelas questões do estudo do texto. Ou seja, não cabe ao leitor concordar ou discordar do texto, uma vez que o livro orienta todos os leitores a uma compreensão uniforme, a qual:

[...] já são resultado de uma interpretação - a do autor do LD interpretação concretizada na própria maneira de se formularem as perguntas e na priorização por determinados fatos que serão objetos das questões. [...] Verifica-se, em alguns manuais, um excesso de perguntas de 'compreensão', que revelam a preocupação do autor em abarcar tudo o que considera essencial a ser compreendido e, dessa forma, guiar a leitura do aluno. (GRIGOLETO, 1999, p. 70)

Frente ao fato de que a leitura no livro didático é, constantemente, realizada pela apresentação do texto e logo após exercícios de compreensão estabelecendo uma mecanicidade para o processo, é importante realizarmos alguns apontamentos mais aprofundados sobre o Estudo do texto.

\section{$2 \mathrm{O}$ estudo do texto no livro didático}

A estrutura do livro didático de apresentar um texto e logo 
após o estudo do texto estabeleceu-se como padrão, conforme pesquisa realizada por Bezerra (2001), já na década de 60. Desde então, muitos estudiosos se interessaram por investigar esse contexto, como, por exemplo, Marcuschi (2001), que chega a uma classificação das perguntas que mais aparecem em LDs de Língua Portuguesa, resultado de análise realizada por ele em vinte e cinco livros do Ensino Fundamental da década de 90, século XX.

\begin{tabular}{|c|c|}
\hline $\begin{array}{l}\text { Tipos de } \\
\text { perguntas }\end{array}$ & Explicitação \\
\hline $\begin{array}{l}\text { 1. A cor do } \\
\text { cavalo branco de } \\
\text { Napoleão }\end{array}$ & $\begin{array}{l}\text { São P muito freqüentes e de perspicácia } \\
\text { mínima, auto-respondidas pela própria } \\
\text { formulação. Assemelham-se às indagações do } \\
\text { tipo: "Qual a cor do cavalo branco de } \\
\text { Napoleão?". }\end{array}$ \\
\hline 2. Cópias & $\begin{array}{l}\text { São as } \mathrm{P} \text { que sugerem atividades mecânicas de } \\
\text { transcrição de frases ou palavras. Verbos } \\
\text { freqüentes aqui são: copie, retire, aponte, indique, } \\
\text { transcreva, complete, assinale, identifique etc. }\end{array}$ \\
\hline 3. Objetivas & $\begin{array}{l}\text { São as } \mathrm{P} \text { que indagam sobre conteúdos } \\
\text { objetivamente inscritos no texto ( } O \text { que, quem, } \\
\text { quando, como, onde...) atividade de pura decodificação. } \\
\text { A resposta acha-se centrada exclusivamente no } \\
\text { texto. }\end{array}$ \\
\hline 4. Inferenciais & $\begin{array}{l}\text { Estas P são as mais complexas; exigem } \\
\text { conhecimento textual e outros, sejam pessoais, } \\
\text { contextuais, enciclopédicos, bem como regras } \\
\text { inferenciais e análise crítica para busca de } \\
\text { respostas. }\end{array}$ \\
\hline 5. Globais & $\begin{array}{l}\text { São as } \mathrm{P} \text { que levam em conta o texto como um } \\
\text { todo e aspectos extra-textuais, envolvendo } \\
\text { processos inferenciais complexos. }\end{array}$ \\
\hline 6. Subjetivas & $\begin{array}{l}\text { Estas } \mathrm{P} \text { em geral têm a ver com o texto de } \\
\text { maneira apenas superficial, sendo que a } \mathrm{R} \text { fica } \\
\text { por conta do aluno e não há como testá-la em } \\
\text { sua validade. }\end{array}$ \\
\hline
\end{tabular}




\begin{tabular}{|l|l|}
\hline 7. Vale-tudo & $\begin{array}{l}\text { São as P que indagam sobre questões que } \\
\text { admitem qualquer resposta não havendo } \\
\text { possibilidade de se equivocar. A ligação com o } \\
\text { texto é apenas um pretexto sem base alguma } \\
\text { para a resposta. }\end{array}$ \\
\hline 8. Impossível & $\begin{array}{l}\text { Estas P exigem conhecimentos externos ao } \\
\text { texto e só podem ser respondidas com base em } \\
\text { conhecimentos enciclopédicos. São questões } \\
\text { antípodas às de cópia e às objetivas. }\end{array}$ \\
\hline $\begin{array}{l}\text { 9. Meta- } \\
\text { lingǘsticas }\end{array}$ & $\begin{array}{l}\text { São as P que indagam sobre questões formais, } \\
\text { geralmente da estrutura do texto ou do léxico, } \\
\text { bem como de partes textuais. }\end{array}$ \\
\hline
\end{tabular}

Quadro 1 - Tipologia das Perguntas de Compreensão em LDP da obra de Marcuschi (2001, p. 52-53)

Marcuschi (2001) esclarece que a existência de perguntas "mistas", que são as que envolvem questões de dois tipos de classificação, porém para quantificação na tabela, considerou-se o peso maior que continham numa das duas partes.

Muito além da apresentação da quantidade de tipos de questões que mais aparecem nos LDs da década de 90, as descrições de cada tipo evidenciam, principalmente, a coexistência de várias concepções de leitura na proposta de trabalho dos materiais analisados. A concepção de leitura como extração expõe-se através das perguntas de cópia e perguntas objetivas, pois elas exigem "apenas que o aluno responda sobre a informação que está expressa no texto" (KLEIMAN, 1993, p. 20); a leitura como atribuição, explicita-se nas questões subjetivas, as quais aceitam "qualquer interpretação de texto realizada pelo aluno" (MENEGASSI; ANGELO, 2005). A taxionomia chega a explicitar também a falta de sedimentação do que é leitura, que se revela a partir das questões que nada tem a ver com a compreensão leitora, como, por exemplo, as questões impossíveis e as de vale-tudo, que podem ser respondidas com qualquer dado, sem nenhuma necessidade de considerar o texto lido.

Para Marcuschi (2001), mesmo com questões que envolvam processos complexos, como as inferenciais e globais, as quais se constituem por uma visão interacionista de leitura, os LDs deixam 
transparecer que "os exercícios de compreensão raramente levam a reflexões críticas sobre o texto e não permitem expansão ou construção de sentido, o que sugere a noção de que compreender é apenas identificar conteúdos" (p. 49 - grifo do autor). Assertiva corroborada pelo fato de que as questões inferenciais e globais, na pesquisa realizada pelo autor, constituem apenas um décimo das questões totais, enquanto que, aquelas fundadas exclusivamente no texto predominam, constituem $70 \%$ do total das questões.

Cabe ainda salientar que Marcuschi (2001) menciona em seus estudos que, embora as perguntas do estudo do texto mais frequentes sejam aquelas que requerem atos mecânicos, existem Estudos do Texto, sem dúvida, em diversos LDs, constituídos pela perspectiva interacionista de leitura, os quais oferecem boas oportunidades de reflexão, levando o aluno à interpretação, não só à compreensão. Tal menção serviu-nos de motivação para a realização desta pesquisa que, portanto, utilizou e ampliou a taxionomia de Marcuschi (2001). Uma segunda justificativa baseia-se no fato de não termos encontrado depois dos estudos desse autor, nenhum outro mais recente com aprofundamentos específicos nas questões de estudo do texto de livros didáticos de Língua Portuguesa.

\section{Análise das atividades de leitura}

O livro didático Linguagem Nova (FARACO; MOURA, 2004), $5^{\mathrm{a}}$ série do Ensino Fundamental oferece 51 textos distribuídos em 4 diferentes seções presentes em 14 unidades de trabalho, cada uma abordando um tema específico e se diversificando em 22 gêneros textuais. Para os 51 textos principais são oferecidas 266 questões de estudo do texto distribuídas em 3 seções: "Ponto de partida", que se configura para todos os textos de abertura de cada unidade; "Estudo do texto", que se apresenta para a seção "Texto 1" e, por vezes, para as seções "Texto 2" e "Texto 3"; e "Ponto de vista", que estuda as seções "Texto 2" e "Texto 3".

Fica evidente, a partir desses números, que esse material não foge ao quadro geral estabelecido para os LDs, em que o estudo do texto é muito presente, ou seja, o que ocorre com a estrutura: texto e logo após o estudo do texto é uma cristalização do trabalho de leitura, 
em que a compreensão leitora se faz por questões determinadas. Para que pudéssemos conhecer também o aspecto qualitativo das questões que compõem o estudo do texto do $\mathrm{LD}$, utilizamo-nos da taxionomia elaborada por Marcuschi (2001).

Importante esclarecermos que optamos por considerar não apenas as perguntas, mas também as respostas marcadas no LD, visto que ambas são partes integrantes do processo de compreensão (TERZI, 1995) e, segundo Magnani (1989) e Kleiman (1989), a fórmula pergunta pronta e resposta marcada revela que o LD espera do leitor uma compreensão uniforme, a qual já é resultado da interpretação do autor do LD frente a um texto. Porém, destacamos que o material não marca respostas para todas as perguntas, ele permite uma idiossincrasia na construção dos sentidos do texto, pois 2,20\% das questões recebem a sugestão de "resposta pessoal".

Analisadas todas as questões, a constatação, exposta na Tabela 3, mais adiante, foi que 195 questões, ou seja, 73,30 \% do total geral se enquadram perfeitamente nas tipologias de Marcuschi (2001), enquanto que 71 questões, $26,70 \%$, por não se enquadrarem em nenhum dos nove itens determinados pelo autor, exigiram a elaboração de novas tipologias. Assim, seguindo a sequência numérica da taxionomia de Marcuschi (2001), os novos tipos foram definidos por envolverem processos que vão além da proposta estabelecida para as questões determinadas como: inferenciais e globais, conceituadas por Marcuschi (2001), generalizadamente, como questões que exigem do aluno conhecimentos textuais e extratextuais, com exceção das questões do tipo Decodificações, as quais abordaremos mais adiante.

Esses novos tipos levam à etapa da interpretação textual, em que a idiossincrasia se revela, permitindo que o aluno possa ter uma atitude responsiva ativa, concordando, discordando, completando, aplicando o texto em sua realidade, entre outras atitudes que se configuram como sendo de um leitor ativo (BAKHTIN, 2003). Pretendendo evidenciar o exposto, apresentamos a tabela 2 com a explicitação e exemplo de cada nova tipologia. 


\begin{tabular}{|c|c|c|}
\hline $\begin{array}{l}\text { Tipos de } \\
\text { perguntas }\end{array}$ & Explicitação & Exemplos \\
\hline 10. Criticidade & $\begin{array}{l}\text { São as que proporcionam } \\
\text { ao leitor posicionamento } \\
\text { crítico frente ao tema que } \\
\text { está sendo abordado. Para } \\
\text { tanto, é necessário que ele } \\
\text { leve em conta, além das } \\
\text { informações contidas no } \\
\text { texto e no contexto, com } \\
\text { igual importância, a } \\
\text { recuperação sobre tudo } \\
\text { aquilo que ele já abordou } \\
\text { em textos anteriores } \\
\text { apresentados pelo material, } \\
\text { como também suas } \\
\text { opiniões pessoais. }\end{array}$ & $\begin{array}{l}\text { 1. Você concorda com a } \\
\text { epígrafe desta unidade: } \\
\text { "Para entender um povo, é } \\
\text { preciso conhecer seu } \\
\text { folclore? Por quê? (pergunta } \\
\text { sem sugestão de resposta) } \\
\text { (p. 163). }\end{array}$ \\
\hline $\begin{array}{l}11 . \\
\text { Confrontos } \\
\text { entre texto e } \\
\text { realidade }\end{array}$ & $\begin{array}{l}\text { São as que levam o aluno a } \\
\text { uma reflexão frente a sua } \\
\text { própria realidade, isto é, } \\
\text { permitem uma interação } \\
\text { diretamente dirigida entre o } \\
\text { tema abordado e a relação } \\
\text { desse tema com a vida } \\
\text { particular do aluno ou da } \\
\text { sociedade na qual ele } \\
\text { convive. }\end{array}$ & $\begin{array}{l}\text { 7.b. Quais } r \\
\text { brincadeiras ainda são } \\
\text { comuns na sua região? } \\
\text { (pergunta sem sugestão de } \\
\text { resposta) (p. 107). }\end{array}$ \\
\hline $\begin{array}{l}\text { 12. Debates } \\
\text { diretos }\end{array}$ & $\begin{array}{l}\text { Exigem explicitamente que } \\
\text { o aluno debata o tema } \\
\text { abordado com seus pares. }\end{array}$ & $\begin{array}{l}\text { 7. O objetivo mais } \\
\text { importante do anúncio é } \\
\text { valorizar os professores ou } \\
\text { anunciar a revista? Discutam } \\
\text { em grupos de três ou quatro } \\
\text { alunos e, depois, alguém } \\
\text { relata para a classe a } \\
\text { conclusão a que a equipe } \\
\text { chegou. Justifique a } \\
\text { resposta. (pergunta sem } \\
\text { sugestão de resposta) (p. } \\
\text { 235). }\end{array}$ \\
\hline
\end{tabular}




\begin{tabular}{|c|c|c|}
\hline 13. Pesquisas & $\begin{array}{l}\text { Solicitam ao aluno pesquisa } \\
\text { sobre o tema, fazendo com } \\
\text { que haja uma interação } \\
\text { entre o tema trabalhado } \\
\text { pela disciplina de Língua } \\
\text { Portuguesa e por outras } \\
\text { disciplinas. }\end{array}$ & $\begin{array}{l}\text { 2.Raptos são frequentes na } \\
\text { mitologia. Pesquise antes de } \\
\text { responder ou pergunte a um } \\
\text { adulto, um advogado } \\
\text { preferencialmente: que pena } \\
\text { a lei brasileira prevê para o } \\
\text { crime de rapto? Resposta: } \\
\text { Prof.(a), o código penal } \\
\text { brasileiro prevê pena de } 2 \text { a } \\
4 \text { anos para os raptos } \\
\text { cometidos mediante } \\
\text { violência, grave ameaça ou } \\
\text { fraude. Há agravantes e } \\
\text { diminuição de pena em } \\
\text { casos específicos. (p. } 77) \text {. }\end{array}$ \\
\hline $\begin{array}{l}14 . \\
\text { Comparações } \\
\text { entre leituras } \\
\text { realizadas }\end{array}$ & $\begin{array}{l}\text { Perguntas que exigem que } \\
\text { o aluno compare leituras } \\
\text { realizadas entre textos } \\
\text { diferentes, mas que } \\
\text { abordem o mesmo tema. }\end{array}$ & $\begin{array}{l}\text { Compare o texto Crianças } \\
\text { de fibra com esse que } \\
\text { acabou de ler. Apesar de } \\
\text { tratarem do mesmo assunto, } \\
\text { que diferenças você pode } \\
\text { notar entre eles? Resposta: } \\
\text { Prof.(a), espera-se que os } \\
\text { alunos percebam que no } \\
\text { primeiro texto as autoras } \\
\text { relatam o cotidiano em } \\
\text { engenhos de açúcar no } \\
\text { Nordeste. Já no segundo, o } \\
\text { jornalista informa o leitor } \\
\text { sobre uma marcha mundial } \\
\text { contra o trabalho infantil. } \\
\text { (FARACO \& MOURA, } \\
\text { 2004, p. 128). }\end{array}$ \\
\hline $\begin{array}{l}15 . \\
\text { Decodificações }\end{array}$ & $\begin{array}{l}\text { Agrupam as perguntas que } \\
\text { especificamente pretendem } \\
\text { trabalhar o vocabulário }\end{array}$ & $\begin{array}{l}\text { 4. Responda: a. Que palavra } \\
\text { do texto indica que as } \\
\text { baleias têm boca grande? } \\
\text { Resposta: Bocarra, no } 1^{\text {a }} \\
\text { parágrafo. (p. } 143) \text {. }\end{array}$ \\
\hline
\end{tabular}

Quadro 2 - Tipologia das Perguntas de Compreensão da obra de Faraco \& Moura (2004)

Salientamos que as perguntas do tipo Debates diretos, dentro de uma perspectiva interacionista, são (ou deveriam ser) inerentes ao processo de leitura, visto que, dentro do processo de construção de 
sentidos de um texto, conforme Silva (1990), deveriam ser criadas situações que permitissem ao aluno constatar significados no texto, o que é idiossincrático, uma vez que cada leitor tem experiências, origens, histórias próprias que são diferentes umas das outras. Por esse motivo, logo na verificação do sentido primeiro do texto, por utilizar-se de seus conhecimentos próprios, o leitor atribui significados individuais ao texto, em seguida, parte para reflexões coletivas, compartilhando com os demais leitores do texto os sentidos verificados; assim, pode transformar o texto, ou seja, construir mais sentidos para ele (SILVA, 1990). Entretanto, na realidade observada no LD, questões desse tipo são raras.

Sobre as perguntas do tipo Comparações entre leituras realizadas, da mesma forma, elas podem ser compreendidas como constituídas por uma concepção interacionista de leitura, pois fazem com que o aluno não se prenda ao texto em si, mas que possa confrontá-lo com outros, os quais podem ser diferentes em construções composicionais e estilo, mas que tratam sobre o mesmo tema. O aluno é colocado em contato com condições de produção diferentes e por isso passa, mesmo que implicitamente, sendo ele ainda um leitor em formação, a utilizarse de procedimentos de recepção diferentes para cada texto. Caso ele já tenha características de um leitor competente, é levado a perceber que se utilizou de procedimentos diferentes na leitura dos textos que então confronta.

Merece ressalva, como anteriormente sinalizado, o tipo Decodificação. Conforme os estudos de Menegassi \& Ângelo (2005), esse tipo poderia se vincular às questões definidas na classificação de Marcuschi (2001) como Objetivas, uma vez que a concepção de leitura, de ambas, constitui-se sob a perspectiva do texto. Tanto as perguntas objetivas, as quais solicitam respostas facilmente identificadas no texto, quanto as que orientam consulta ao dicionário, as quais "correspondem à crença de que a força das palavras consiste no seu significado de dicionário e não na sua funcionalidade no conjunto do texto" são concebidas pela abordagem teórica estruturalista (MENEGASSI; ANGELO, 2005, p. 21). No entanto, não poderíamos infringir os critérios estabelecidos por Marcuschi em sua classificação, restandonos então a criação de um novo item de classificação.

Agregado ao tipo Decodificações, consideramos outras três questões que, em essência, não são perguntas, mas na verdade uma 
orientação para o modo de se processar a leitura de um texto. Nesta orientação, o que se pretende é a adequada oralização da palavra escrita (MENEGASSI; ANGELO, 2005). Por exemplo: “3. Leia o poema em voz alta. Na sua opinião, as rimas e a repetição de palavras dão sonoridade ao poema?” (FARACO; MOURA, 2004, p. 109).

Enfim, esclarecidas e exemplificadas todas as questões que constituem o Estudo do texto da obra de Faraco \& Moura (2004), apresentamos a Tabela 3 para um enquadramento de todas as questões:

\begin{tabular}{|c|c|c|}
\hline $\begin{array}{l}\text { Tipo de pergunta } \\
\text { participante da } \\
\text { taxionomia } \\
\text { de Marcuschi (2001) }\end{array}$ & $\begin{array}{l}\text { Número de } \\
\text { questões }\end{array}$ & $\begin{array}{c}\text { Percentual em } \\
\text { relação ao total de } \\
\text { questões }\end{array}$ \\
\hline 1.A cor do cavalo ... & 0 & \\
\hline 2.Cópias & 18 & \\
\hline 3.Objetivas & 26 & \\
\hline 4.Inferênciais & 66 & \\
\hline 5.Globais & 40 & \\
\hline 6.Subjetivas & 5 & \\
\hline 7.Vale-tudo & 12 & \\
\hline 8.Impossíveis & 5 & \\
\hline 9.Meta-lingüísticas & 23 & \\
\hline TOTAL & 195 & $73,30 \%$ \\
\hline \multicolumn{3}{|l|}{ Novos Tipos } \\
\hline 10. Criticidade & 23 & \\
\hline $\begin{array}{l}\text { 11. Confronto entre texto } \\
\text { e realidade }\end{array}$ & 15 & \\
\hline 12. Debates direto & 5 & \\
\hline 13. Pesquisas & 13 & \\
\hline $\begin{array}{l}\text { 14. Comparações entre } \\
\text { leituras realizadas }\end{array}$ & 12 & \\
\hline 15. Decodificações & 3 & \\
\hline TOTAL & 71 & $26,70 \%$ \\
\hline TOTAL GERAL & 266 & \\
\hline
\end{tabular}

Quadro 3 - Tabela geral das questões que constituem o Estudo do Texto da obra de Faraco \& Moura (2004) 
Frente ao quadro geral, elaboramos, ainda, a Tabela 4 para visualização da constatação de que as questões do Estudo do texto da obra de Faraco \& Moura (2004) se constituem, predominantemente, pela perspectiva interacionista de leitura (LEFFA, 1999),

\begin{tabular}{|l|l|l|}
\hline \multicolumn{1}{|c|}{ Concepções } & \multicolumn{1}{|c|}{ Tipos de questões } & \multicolumn{1}{c|}{$\begin{array}{c}\text { \% sobre o } \\
\text { total } \\
\text { de questões }\end{array}$} \\
\hline $\begin{array}{l}\text { Falta e sedimentação } \\
\text { do que é leitura }\end{array}$ & Impossíveis & 1,88 \\
\hline $\begin{array}{l}\text { Concepção de leitura } \\
\text { na perspectiva do } \\
\text { leitor }\end{array}$ & Subjetiva e Vale-tudo & 6,39 \\
\hline $\begin{array}{l}\text { Concepção de ensino } \\
\text { tradicionalista } \\
\text { (gramática da língua) }\end{array}$ & Meta-lingüística & 8,64 \\
\hline $\begin{array}{l}\text { Concepção de leitura } \\
\text { na perspectiva do } \\
\text { texto }\end{array}$ & Cópia, Objetiva e Decodificação & 17,66 \\
\hline $\begin{array}{l}\text { Concepção de leitura } \\
\text { na perspectiva } \\
\text { interacionista }\end{array}$ & $\begin{array}{l}\text { Inferenciais, Globais, Criticidade, } \\
\text { Confrontos entre texto e } \\
\text { realidade, Debates Direto, } \\
\text { Pesquisas, Comparações entre } \\
\text { leituras realizadas }\end{array}$ & $\mathbf{6 5 , 4 3}$ \\
\hline
\end{tabular}

Quadro 4 - Tabela das concepções que constituem o Estudo do Texto da obra de Faraco \& Moura (2004)

Evidencia-se, então, que $65,43 \%$ do total geral das questões se configuram pela perspectiva interacionista de leitura, o que ocorre somando-se questões Inferenciais, Globais, Criticidade, Confrontos entre texto e realidade, Debates Direto, Pesquisas, Comparações entre leituras realizadas. Do restante das questões, 17,66\% configuram-se dentro da perspectiva do texto (LEFFA, 1999), sendo elas Cópia, Objetivas e de Decodificação; 8,64\% são Meta-linguísticas, as quais constituem a concepção de ensino tradicional, preocupada em utilizarse do texto como pretexto para o ensino da gramática da língua; 6,39\% representam a perspectiva do leitor (LEFFA, 1999) por meio das questões dos tipos Subjetivas e Vale-tudo; e 1,88 \% são consideradas 
perguntas que em nada contribuem com o processo leitor, são do tipo Impossíveis.

Por fim, é necessário destacar que, assim como os livros analisados por Marcuschi (2001), o Estudo do Texto da obra de Faraco \& Moura (2004) também se organiza pela coexistência de diferentes concepções de leitura, mas é a concepção interacionista a que predomina. Mesmo assim, o que acaba por ocorrer é o estabelecimento da formatação: ler e responder a exercícios. São, na média, 5,21 questões por texto. Esta afirmativa pode ser legitimada pela proposta apresentada para o texto da Unidade 12, seção “Texto 2", em que se pede para o próprio aluno elaborar questões de estudo:

Você já respondeu a muitas questões de estudo do texto formuladas por nós, em outras unidades deste livro. Agora chegou a sua vez de fazer esse trabalho. Reúna-se com quatro colegas. Cada grupo elabora três questões sobre o assunto do texto lido, escrevendo-as numa folha avulsa, para um outro grupo responder. Em outra folha, cada grupo responde às questões que formulou. As folhas de questões são trocadas entre os grupos. A seguir, haverá uma discussão sobre as respostas entre o grupo que fez as questões e o que respondeu. (FARACO; MOURA, 2004, p. 211).

Por assim se estruturar, podemos compreender que o LD acredita que garantindo a fórmula, garante a compreensão do texto lido.

\section{Considerações finais}

Apresentada a expansão das tipologias demarcadas por Marcuschi (2001) que ocorreu em análise às questões de Estudo do texto da obra da Faraco \& Moura (2004), principalmente no que se refere ao enquadramento dos novos tipos à perspectiva interacionista de leitura, fica evidente que o livro Linguagem Nova, assim como orientam os PCNs, concebe a leitura, predominantemente, como interacionista. Fato que foi de encontro aos livros analisados por Macuschi (2001), configurados pelo predomínio de questões fundadas 
exclusivamente no texto, $70 \%$ do total de questões foram demarcados como cópias e objetivas.

Linguagem Nova (FARACO; MOURA, 2004) promove uma significativa expansão do processo de extração (KATO, 1990) e atribuição (LEFFA, 1999), permitindo que o aluno leve em conta o texto como um todo, refletindo e inter-relacionando o que o autor oferece por meio do texto e o que o aluno oferece ao texto a partir de suas experiências e conhecimentos próprios, permitindo a etapa de interpretação do texto.

Contudo, o livro determina em que momento o aluno pode sair da etapa de compreensão e partir para a interpretação, pois é ele, o livro, que elabora as questões para o estudo do texto. Mesmo assim, não consideramos o descarte da fórmula perguntas e respostas como solução. Urge, por conseguinte, que o LD passe a considerar a sala de aula, assim como Souza (1995, p, 21) "uma arena de conflitos de vozes e valores mutáveis e concorrentes". Ou seja, há uma urgência de que o livro didático promova ainda mais o debate, a discussão, a troca de experiências, então chamadas de conflito, que possam ocorrer entre professores e alunos, por intermédio do livro didático.

\section{Referências}

BAKHTIN, M. Estética da criação verbal. 4. ed. São Paulo: Martins Fontes, 2003.

BEZERRA, M.A. Textos: seleção variada e atual. In: DIONISIO, A. P.; BEZERRA, M. A. O livro didático de português: múltiplos olhares. Rio de Janeiro: Lucerda, 2001, p. 33-45.

BRASIL. Secretaria de Educação Fundamental. Parâmetros curriculares nacionais: língua portuguesa. Brasília. Secretaria de Educação Fundamental, 1997.

Secretaria de Educação Fundamental. Programa Nacional do Livro Didático. Guia de livros didáticos 2005. v. 2. Língua Portuguesa. Brasília: Secretaria de Educação Infantil e Fundamental, 2004. 
COLOMER, T.; CAMPS, A. Ensinar a ler, ensinar a compreender. Tradução Fátima Murad. Porto Alegre: Artmed, 2002.

CORACINI, M.J. O livro didático nos discursos da lingüística aplicada e da sala de aula. In CORACINI, M.J. (Org.). Interpretação, autoria e legitimação do livro didático: língua materna e língua estrangeira. Campinas, SP: Pontes, 1999, p.17-26.

DELL'ISOLA, R.L.P. A interação sujeito-linguagem em leitura. In: MAGALHÃES, I. (Org.). As múltiplas faces da linguagem. Brasília: UNB, 1996, p. 69-75.

FARACO, C.; MOURA, F. Linguagem Nova. 17. ed. São Paulo: Ática, 2004.

GRIGOLETTO, M. Leitura e Funcionamento Discursivo do Livro Didático. In: CORACINI, M. J.R.F. (org.). Interpretação, autoria e legitimação do livro didático: língua materna e língua estrangeira. Campinas, SP: Pontes, 1999, p. 67-77.

KATO, M.A. O aprendizado da leitura. 3. ed. São Paulo: Martins Fontes, 1990.

KLEIMAN, A. Leitura: ensino e pesquisa. Campinas, SP: Pontes, 1989. . Oficina de leitura: teoria e prática. Campinas, SP: Pontes, 1993.

. A. Texto \& Leitor: aspectos cognitivos da leitura. 7. ed. Campinas, SP: Pontes, 2000.

LEFFA, V.J.; PEREIRA. A. E. (Orgs.). O ensino da leitura e produção textual. Pelotas: Educat, 1999.

MAGNANI, M.R.M. Leitura, literatura e escola: sobre a formação do gosto. São Paulo: Martins Fontes, 1989.

MARCUSCHI, L.A. Compreensão de texto: algumas reflexões. In: DIONISIO, A. P.; BEZERRA, M.A. (Org.). O livro didático de Português: múltiplos olhares. Rio de Janeiro: Lucerna, 2001, p. 46-59. 
MENEGASSI, R.J.; ANGELO, C. M. P. Conceitos de leitura. In: MENEGASSI, R.J. (Org.). Leitura e ensino. Maringá: EDUEM, 2005, p. $15-43$.

SAVIOLI, F.R. Livro didático: liberdade ou opressão? In: GREGOLIN, M.R.V.; LEONEL, M.C.M. (org.). O que quer o que pode esta lingua? Brasil/ Portugual: o ensino de língua portuguesa e de suas literaturas. Araraquara, SP: FCL-UNESP-Ar, 1997, p.113-126.

SILVA, E.T. A leitura no contexto escolar. In: MAGNANI, M.A.(Coord. Geral). Leitura: caminhos da aprendizagem. São Paulo: FDE, 1990, p. 63-70.

Criticidade e leitura: ensaios. Campinas, SP: Mercado das Letras: Associação de Leitura do Brasil, 1998.

SOLÉ, I. Estratégias de leitura. Tradução Cláudia Schilling. 6. ed. Porto Alegre: ArtMd, 1998.

SOUZA, L.M.T.M. O conflito de vozes na sala de aula. In: CORACINI, M. J.R.F. (Org.). O jogo discursivo na aula de leitura: língua materna e língua estrangeira. Campinas, SP: Pontes, 1995, p. 21-26.

STRIQUER, M.S.D. Os objetivos de leitura no livro didático. 2007. Dissertação (Mestrado em Letras) - Universidade Estadual de Maringá, Maringá.

TERZI, S.B. A construção da leitura: uma experiência com crianças de meios iletrados. Campinas, SP: UNICAMP, 1995. 